\title{
El derecho subjetivo entre la escolástica y la modernidad. La posición de Francisco Suárez
}

Subjective Right between Scholasticism and Modernity. The Place of Francis Suárez

Felipe Widow Lira

Pontificia Universidad Católica de Chile ffwidow@uc.cl

DOI: https://doi.org/10.15366/bp2021.26.010

Bajo Palabra. II Época. No26. Pgs: 201-220 
Recibido: 17-09-2020

Aceptado: 9-10-2020

Este trabajo forma parte del proyecto Fondecyt $n^{\circ} 11171125$,

financiado por la Agencia Nacional de Investigación y Desarrollo

(ANID, ex Conicyt), del cual el autor es investigador responsable.

Resumen

Contra la tesis de Villey según la cual la sola presencia del derecho subjetivo es indicio de nominalismo (lo que haría nominalista al conjunto de la segunda escolástica), se sostiene que la relación de los teólogos-juristas españoles del XVI y XVII con la modernidad no es unívoca. Se muestra la figura de Francisco Suárez como ejemplar de las tensiones internas propias de una teoría jurídica que, aún tomista en algunos aspectos, integra elementos contradictorios, que le llevan a exaltar el derecho subjetivo como la realidad jurídica primordial, eclipsando, así, el lugar de lo justo y redefiniendo la ley.

Palabras clave: derecho subjetivo, escolástica, Francisco Suárez, modernidad jurídica, nominalismo, Villey.

\section{Abstract}

Against Villey's thesis according to which the sole presence of subjective right is an indication of nominalism (which would make the whole of the second scholasticism nominalist), it is argued that the relationship of the Spanish theologians-jurists of the 16th and 17 th centuries with modernity is not univocal. The figure of Francisco Suárez is shown as an example of the internal tensions of a legal theory that, still Thomistic in some aspects, integrates contradictory elements, which lead him to exalt subjective right as the primary juridical reality, thus eclipsing the place of just and redefining the law.

Keywords: subjective right, Scholasticism, Francis Suárez, legal modernity, nominalism, Villey. 


\section{Introducción}

A NADIE SE LE ESCAPA que, en un lapso de tiempo relativamente breve, que podemos situar entre los siglos XIV y XVII, la doctrina y las instituciones jurídicas del occidente cristiano sufrieron un proceso de transformación profunda. El resultado de esa transformación es lo que se ha llamado 'modernidad jurídica', y lo que ha quedado atrás, superado por la novedad moderna, es el derecho de la 'cristiandad medieval'. Este tipo de categorías históricas suponen, siempre, una simplificación que puede generar equívocos que hay que evitar: no se trata, por supuesto, de dos cuerpos doctrinales ni esquemas institucionales unívocos y monolíticos. En el caso de la modernidad esto es palmario: una de sus notas más distintivas es que la transformación no se detiene, sino que tanto la doctrina como las instituciones adquieren un carácter inquieto que les lleva a un estado de permanente evolución y re-evolución. Y, aunque sin la intensidad de la modernidad, también hay transformaciones jurídicas profundas en el mundo medieval. Pero lo cierto es que las revoluciones jurídicas modernas están unificadas por sus principios más universales, y lo mismo se puede decir de las transformaciones medievales. Y es, precisamente, entre unos y otros principios que se encuentra el abismo que permite sostener aquellas categorías a pesar de la simplificación que importan: es innegable que entre los siglos XIV y XVII se ha dado un giro copernicano desde el derecho de la cristiandad medieval (o, si se prefiere, del mundo clásico y medieval -dada la unidad fundamental de principios entre el orden jurídico romano y el cristiano que le sucede-) al derecho de la modernidad. Y una de las claves conceptuales para reconocer y entender este giro pasa por advertir las transformaciones que se dan en la comprensión de tres realidades jurídicas - que han sido llamadas 'derecho'-y de las relaciones que guardan entre sí. Estas realidades son: lo justo, la ley y la facultad o poder de un sujeto para exigir algo de otros. Es más, se podría resumir el giro copernicano señalado en tres fenómenos entrelazados: el eclipse de lo justo, el amanecer de los derechos y la consecuente redefinición de la ley. En efecto, si hay algo en lo que la modernidad jurídica es como un negativo de la tradición clásica y medieval es en el reemplazo de lo justo por el derecho subjetivo como la realidad jurídica primaria y fuente de significación de las demás.

En la historia de este giro ocupa un lugar muy relevante la segunda escolástica o escolástica española. La razón es que esos teólogos-juristas del siglo XVI y comienzos 
del XVII, que han transformado Salamanca en un nuevo París, constituyen una bisagra entre el mundo medieval y el moderno: por una parte, han rescatado el método escolástico y han situado la obra de Tomás de Aquino en el centro de la reflexión intelectual europea; por otra, pertenecen a un tiempo en el que la unidad religiosa ha estallado por los aires, el humanismo ha penetrado casi todos los espacios de la cultura, y la política ha virado del régimen mixto a una progresiva concentración de poder de la que habría de emerger la burocracia estatal. Esta misma posición de gozne entre una cultura jurídica que se muere y otra que nace, ha hecho muy difícil juzgar pacíficamente su lugar en esta historia: hay quien los ve como los últimos representantes del mundo clásico, pero no son pocos quienes los sitúan como proto-modernos, verdaderos responsables de la revolución jurídica de la modernidad.

En este trabajo se aborda esta discusión en uno de los puntos en que la situó el autor que más la animó durante el siglo pasado: Michel Villey. Concretamente, se enfrenta el problema de la relación entre derecho subjetivo y nominalismo -clave de la modernidad jurídica, según el propio Villey- y el modo equívoco en que esta relación aparece en la segunda escolástica. Se mira a la figura de Francisco Suárez como ejemplar de las tensiones internas propias de una teoría jurídica en tránsito entre dos paradigmas, y se procura mostrar cómo es que Suárez, aún sin abandonar completamente el puerto de la doctrina tomista, ya ha integrado en su exposición elementos ajenos a aquella-incluidas algunas trazas de nominalismo-, que le llevan a exaltar el derecho subjetivo como la realidad jurídica primordial, eclipsando, así, el lugar de lo justo y redefiniendo la ley.

\section{Villey, el derecho subjetivo y la segunda escolástica}

Cuando Michel Villey propuso su tesis de que el origen del concepto de derecho subjetivo se hallaba en Ockham, y de que tal concepto era la coherente y necesaria consecuencia jurídica del nominalismo y el voluntarismo, lo hizo en unos términos que pretendían señalar una clarísima línea divisoria entre el pensamiento jurídico clásico y medieval, por una parte, y el pensamiento jurídico moderno, por la otra. En lúcida expresión de Brian Tierney: "Villey ha ideado una suerte de universo maniqueo. Hay un mundo del pensamiento aristotélico, lleno de luz y dulce razón, y un mundo del pensamiento ockhamista, donde todo es oscuridad y voluntad ciega" ${ }^{1}$. Desde la perspectiva de Villey, en la comprensión del derecho y la

\footnotetext{
${ }^{1}$ Tierney, Brian. The Idea of Natural Rights. Studies on Natural Rights, Natural Law and Church Law, 1150-1625. Grand Rapids-Michigan, B. Eerdmans Publishing Co., 2001, p. 30. (Todas las traducciones son propias, salvo que se indique expresamente al traductor).
} 
justicia hay un antes y un después de Ockham, y la clave para identificar la novedad moderna en sede jurídica es la presencia del nominalismo voluntarista bajo la forma de la idea de un derecho que no es ya la ipsa res iusta de Tomás de Aquino, sino una facultas: un poder moral radicado en un individuo, "licencia para realizar tal o cual conducta, porque esa conducta es mandada, o permitida, por una ley" 2 .

Usando de este criterio como una espada afilada, Villey carga no sólo contra los autores jurídicos paradigmáticos de la primera modernidad -Grocio, Hobbes, Pufendorf, Leibniz, Locke...- para mostrar en ellos su dependencia de Ockham, sino también contra todo aquel que admita la existencia del derecho subjetivo, aun si intenta integrarlo en una teoría que se sitúe en continuidad con el pensamiento clásico y medieval. Es el caso de la escolástica española de los siglos XVI y XVII y de casi todos sus sucesores en los campos del iusnaturalismo tomista. Según Villey, "[l]os escolásticos espańoles, tanto dominicos (Vitoria, Soto) como jesuitas (Suárez, Molina)"3 (como si la escolástica española fuese una escuela monolítica, sin mayores diferencias de Vitoria a Suárez ${ }^{4}$-aunque habría que conceder que, en sede jurídica y asumida la medida villeyana, las diferencias entre unos y otros deberían ser puramente accesorias, puesto que todos aceptan la existencia de un poder o facultad al que llaman derecho-), si bien "se muestran rompiendo con el sistema de Ockham" ${ }^{5}$ y enseñan desde la lectura de la obra de Santo Tomás y los comentarios de la misma ("los comentarios más que la lectura" ${ }^{6}$, añade con sorna), al punto que "han adquirido la reputación de ser sus fieles continuadores" preguntarse si "han tergiversado la lección de Santo Tomás, deformado subrepticiamente la doctrina tradicional católica del derecho natural, pasando de Santo Tomás al tomismo (que difieren muchísimo)" ${ }^{8}$. Por supuesto, la respuesta de Villey es ro-

\footnotetext{
${ }^{2}$ Villey, Michel. Le droit et les droits de l'homme. Paris, Presses Universitaires de France, 1983, p. 127.

${ }^{3}$ Idem.

${ }^{4}$ Quien, sorprendentemente, realiza una identificación semejante de los diversos autores y escuelas de la escolástica española, es el p. Avelino Folgado. Sorprendente, porque lo hace en la dirección exactamente contraria a la de Villey: en su opinión, Molina y Suárez, como Vitoria y Soto, sostienen unas ideas perfectamente tomistas del derecho y la ley. Véase Folgado, Avelino. Evolución histórica del concepto de derecho subjetivo. Estudio especial de los teólogos-juristas españoles del siglo XVI. San Lorenzo de El Escorial, Pax Juris - Escurialensium Utriusque Studiorum Scerpta, 1960, pp. 49-55.

${ }^{5}$ Villey, Michel. Le droit et les droits de l'homme. Op. cit., p. 126. Vale la pena hacer notar que la redacción francesa dice affectèrent de briser avec le système de Guillaume d'Occam, que puede ser traducida como se ha hecho aquí, pero que también puede ser leída como 'simulan romper con el sistema de Guillermo de Ockham'. Parece difícil que esta ambivalencia haya escapado a Villey, en lo cual se muestra la dureza con que juzga a estos autores, a quienes acusa no ya tan sólo de nominalismo, sino de un tomismo afectado, inauténtico.

${ }^{6}$ Ídem.

7 Ídem.

${ }^{8}$ Villey, Michel. La formation de la pensée juridique moderne. Paris, Presses Universitaires de France, 2a edición, 2013, p. 338.
} 
tunda: los escolásticos españoles del XVI y el XVII no son auténticos continuadores de la filosofía -al menos jurídica- de Tomás de Aquino:

"[Q]ue estos españoles hayan seguido la línea de Santo Tomás es extremadamente discutible. Es falso que hayan adherido a la mayor parte de sus ideas, al menos en la materia que nos interesa. Usando de un método dialéctico muy degenerado, han asociado a los textos de la Suma otras 'autoridades' de moda. El resultado es una mezcla, un compromiso, entre escotismo, nominalismo y teología de Santo Tomás"

La tesis central de Villey en lo que concierne al origen y naturaleza del derecho subjetivo -esto es, que este origen se encuentra en Ockham y está íntima y esencialmente conectado con el nominalismo y el voluntarismo del inglés-, ha sido fuertemente discutida y en muchos aspectos superada. El frente de esa discusión podría dividirse en tres: la cuestión histórica de si hay, o no, derecho subjetivo antes de Ockham; la cuestión conceptual de si la noción moderna de derecho subjetivo -presente en Hobbes, Locke, Kant, las primeras formulaciones de los derechos del hombre, etc.- está unificada, o no, por su dependencia del nominalismo y voluntarismo ockhamista; y, por último, la cuestión -propia de la filosofía jurídica del iusnaturalismo- de si la teoría clásica de la ley natural es necesariamente incompatible con la afirmación del derecho subjetivo.

En el primer frente, puede decirse que la tesis histórica de Villey ha sido fundadamente contestada por el trabajo de Brian Tierney $-y$ otros que han seguido su estela ${ }^{10}$-, que ha mostrado la presencia explícita de una noción de derecho como facultad en los canonistas del siglo XII ${ }^{11}$. La discusión no ha cesado en lo que toca a la presunta presencia implícita o confusa de tal noción en el derecho romano ${ }^{12} \mathrm{y}$ en autores medievales no nominalistas -como el mismísimo Tomás de Aquino ${ }^{13}$-, pero la posibilidad de que el "inventor" del derecho subjetivo sea Ockham parece quedar definitivamente excluida por virtud de los argumentos de Tierney. La superación de este aspecto de la tesis de Villey es, al menos, la punta

\footnotetext{
${ }_{9}$ Villey, Michel. Le droit et les droits de l'homme. Op. cit., p. 126.

${ }^{10}$ Véase, entre otros, Reid, Charles J. Jr. "The Canonistic Contribution to the Western Right Tradition : An Historical Inquiry". Boston College Law Review vol. 33, 1991; Pennington, Kenneth. "The History of Rights in Western Thought". Emory Law Journal, vol. 47, 1998.

${ }^{11}$ Véase Tierney, Brian. The Idea of Natural Rights. Studies on Natural Rights, Natural Law and Church Law, 11501625. Op. cit., pp. 13-78.

12 Véase Megías, José Justo "El derecho subjetivo en el derecho romano (un estado de la cuestión)", en Revista de Estudios Histórico-Jurídicos 25, 2003, pp. 35-54.

13 Véase, por ejemplo, Tierney, Brian. "Natural Law and Natural Rights. Old Problems and Recent Approaches", The Review of Politics, Vol. 64, n 3, 2002; Finnis, John. "Aquinas on ius and Hart on Rights: A Response to Tierney", The Review of Politics vol. 64, n 3, 2002.
} 
del hilo que permite superar otro de los aspectos de su propuesta: si la noción del derecho como facultad se halla explícitamente presente en los canonistas del siglo XII, no puede ser esencialmente dependiente del nominalismo, porque Ockham es quien da sistematicidad y fuerza a la solución nominalista del problema de los universales, que en tiempos de aquellos canonistas sólo había aparecido parcial y tímidamente en autores como Roscelín o Abelardo ${ }^{14}$, sin el desarrollo y la difusión necesarios como para producir una transformación de la teoría jurídica. En otras palabras, si es que la comprensión del derecho como una facultad es una innovación de las escuelas medievales de derecho canónico, habrá que buscar las razones de este giro en unas fuentes que no son el nominalismo ${ }^{15}$. Esto, a su vez, tiene como consecuencia una reformulación del problema en el tercer frente de la discusión: en la perspectiva de Villey, la razón de la incompatibilidad radical entre la teoría clásica de la ley natural y la afirmación del derecho subjetivo radicaba, precisamente, en el carácter inevitablemente nominalista de éste último. Puesto en cuestión tal carácter, se abre el espacio para intentar una teorización del derecho subjetivo en continuidad con la teoría clásica de la ley natural. Esta es, de hecho, la posición de muchos autores iusnaturalistas que se han hecho cargo de la objeción de Villey.

De este modo, quizá el único frente en el que los argumentos de Villey conservan vigencia es el segundo: ¿puede afirmarse que hay un derecho subjetivo formalmente moderno? ¿y que el principio de unidad de teorías del derecho tan diversas como las que podemos hallar en Hobbes, Locke, Kant o Mill, es su dependencia del nominalismo y el voluntarismo que se han expandido en la filosofía a partir de Ockham? En el fondo, lo que encontramos en Villey es una tesis iusfilosófica: la asociación esencial entre derecho subjetivo (moderno) y nominalismo, y una construcción histórica ad-hoc para sostener su tesis filosófica. La construcción histórica no se ha sostenido y, ante los embates de objeciones bien fundamentadas, ha caído como un castillo de naipes. Pero, puesto que tal construcción era posterior a la tesis filosófica, la debilidad de aquella no significa, necesariamente, la falsedad de la proposición que la precedía. En todo caso, lo que hacía falta -para independizar a la tesis filosófica de la histórica- era añadir, al derecho subjetivo, el apellido de 'moderno'.

\footnotetext{
${ }^{14}$ Véase Rego, Francisco. La polémica de los universales: sus autores y sus textos. Buenos Aires, Gladius, 2005.

15 Thierry Sol muestra, de hecho, que en los orígenes canónicos del derecho subjetivo éste no aparece en oposición o competencia con el derecho objetivo (en sentido clásico, esto es, como la cosa justa), sino como una realidad jurídica enmarcada dentro de un cuadro más amplio, que es el del derecho objetivo [Véase Sol, Thierry. "La notion de ius en droit sacramentaire chez Gratien et les Décrétistes”. Ius Ecclesiae. Rivista internacionales di Diritto Canonico. Vol. XXVII, $n^{\circ} 2$ 2, 2015]. Pero aquella oposición sería la consecuencia necesaria de una asociación esencial entre derecho subjetivo y nominalismo, según las premisas del propio Villey.
} 
En otro lugar ${ }^{16}$, hemos intentado mostrar que, en este punto y hecha la precisión descrita, el argumento de Villey es consistente: parece indesmentible la consecuencia lógica que existe entre los supuestos metafísicos y gnoseológicos del nominalismo de Ockham y algunos de los más importantes hitos teóricos de la modernidad jurídica. Y es bastante claro que uno de esos hitos es el desarrollo del concepto de derecho subjetivo que, no obstante su carácter multiforme porque es evidente que los diversos autores modernos no entienden lo mismo por el derecho como facultad-, conserva unas notas comunes que persisten de una teoría a otra, y que tales notas están todas vinculadas, en sus raíces, con el nominalismo y el voluntarismo. En efecto, en todas aquellas teorías (aunque no en todas en el mismo grado y con la misma intensidad) se puede encontrar una negación -al comienzo implícita y más tarde expresa- de una naturaleza humana universal como supuesto de la inteligibilidad del derecho; en todas ellas emerge el individuo monádico como el único sustrato de la realidad jurídica; y en todas ellas, también, es la voluntad indeterminada del individuo (libertad negativa) la fuente principal de la que mana el derecho. Y de todo esto parece emerger como resultado la exaltación del derecho subjetivo como la primera realidad jurídica y principal acepción del ius, puesto que ya para los nominalistas del siglo XIV, "[l]a manifestación primaria de la vida jurídica era un dominium, potestas, o facultas ad libitum que correspondía a cada hombre antes de intervenir el derecho natural o el derecho de origen humano" 17

Ahora bien, si se concede esta tesis, entonces adquiere renovado sentido una de las cuestiones que Villey había mal resuelto con su frágil construcción histórica: ¿cuál es el lugar que ocupan los teólogos juristas españoles del XVI y el XVII en el tránsito de las concepciones jurídicas clásicas a las modernas? ¿Cuál, específicamente, es la noción de derecho subjetivo que integran en sus sistemas? $¿$ Tiene el derecho como facultad, ya en ellos, las notas comunes que luego es posible reconocer en las teorías propiamente modernas? Por supuesto que ya no es posible la gruesa respuesta de Villey: no basta con descubrir que llaman derecho a una facultad para concluir que están inficionados de nominalismo. Además, puesto que es imposible tal asociación lógica, tampoco es aceptable hacer un juicio general sobre el conjunto de la escolástica española: Vitoria, Soto, Molina o Suárez son, en muchos aspectos relevantes para esta discusión, autores que guardan entre sí grandes y profundas diferencias. Pero sigue siendo lícito y necesario

\footnotetext{
${ }^{16}$ Véase Widow Lira, Felipe. "Los orígenes de la noción moderna de derecho subjetivo. ¿Ha sido superada la tesis de Michel Villey?”. Forum. Suplemment to Acta Philosophica, vol. 5/2, 2019.

${ }_{17}$ Carpintero, Francisco. "Las personas como síntese: la autonomía en el derecho”. En Leite De Campos, Diego y Juny De Abreu Chillenato, Silmara. Pessoa humana e direito. Coimbra, Edicoes Almedina, 2009, p. 162.
} 
preguntarse por la posición que estos autores ocupan en ese difícil tránsito del pensamiento jurídico desde el mundo medieval al moderno. En lo sucesivo se intentará mostrar que esa posición es ambigua: aunque los escolásticos españoles son sinceramente tomistas, también son hijos de su tiempo, que es un tiempo radicalmente distinto del que vivió el dominico de París. Esto les lleva a tensiones internas que resuelven en distintas direcciones: unos hacia la tradición clásica y otros hacia la moderna (y, tratándose de cuestiones diferentes, cada uno ni siquiera sigue siempre la misma dirección). Sin embargo, parece razonablemente fundada la afirmación de que durante la breve historia de la segunda escolástica se produce, en algún momento, un quiebre. Y que si autores como Vitoria o Soto -no obstante alguna novedad ${ }^{18}$ - pertenecen en lo esencial a la misma tradición jurídica de Santo Tomás, no se puede decir lo mismo de Molina o Suárez ${ }^{19}$. No es posible hacerse cargo de esta hipótesis de manera integral, de modo que el argumento de la segunda parte de este trabajo se centrará en el jesuita Francisco Suárez, figura central de la tercera generación de la escolástica espańola (en la que le acompañan otros jesuitas, como los padres Molina y Vázquez). Como ha mostrado Francisco Carpintero -entre otros, pero él de un modo especialmente nítido-, en esta tercera generación aparecen contradicciones que se resuelven, ya claramente, en dirección a la modernidad ${ }^{20}$. Y en Suárez, además, esto ocurre de un modo especialmente expreso con su concepción del derecho y la relación que establece entre el ius como lo justo y el ius como facultad moral (y con la correspondiente redefinición de la ley). Lo sorprendente es que la resolución de las contradicciones en dirección a la modernidad la hace, Suárez, como si hubiese perfecta continuidad entre sus posturas y aquellas de Tomás de Aquino. Incluso, como advierte Carpintero: "[c]uando [Suárez] sienta doctrinas en las que se aparta toto coelo de la visión tomista del Derecho natural, entonces se remite expresamente a la obra del Aquinate. Cuando no es así, se refiere a los «thomistae» como seres lejanos" ${ }^{21}$.

\footnotetext{
${ }^{18}$ Guzmán Brito afirma que tanto Vitoria como Soto introducen el derecho como facultad, exclusivamente, como un elemento explicativo del derecho privado, en aquello que dice relación con la propiedad. Véase Guzmán Brito, Alejandro. El derecho como facultad en la neoescolástica española del siglo XVI. Madrid, Iustel, 2009, pp. 39-40. En la misma línea, Megías, José Justo. Propiedad y derecho natural en la historia. Cádiz, Servicio de Publicaciones de la Universidad de Cádiz, 1994, pp. 120 y ss.

19 Sobre las diferencias fundamentales que pueden encontrarse entre los extremos de Vitoria y Soto, por una parte, y Molina y Suárez, por la otra, véase, entre otros lugares: Carpintero, Francisco. "Los escolásticos españoles en los inicios del liberalismo político y jurídico". Revista de Estudios Histórico-Jurídicos 25, 2003, pp. 342-347; Rodríguez Puerto, Marcial. "Escolásticos espańoles y subjetivismo moderno (un comentario sobre el concepto de derecho en Luis de Molina y Francisco Suárez)". Ingenium 5, 2011, pp. 171 y ss.

${ }^{20}$ Véase Carpintero, Francisco. Historia breve del derecho natural. Madrid, Colex, 2009, pp. 124-144.

21 Ibid., p. 131.
} 


\section{El derecho: de Tomás de Aquino a la modernidad, pasando por Suárez}

Cuando Suárez enfrenta la Cuestión del Significado de la voZ iUs, en el comienzo de su De legibus ${ }^{22}$, sigue expresamente la exposición que Tomás de Aquino hace sobre el mismo asunto en la cuestión 57 de la secunda secundae de la Suma Teológica. Así, tras describir lo que él afirma que ha de ser tomado como el sentido primario y principal de la voz ius, añade que "Santo Tomás dijo que ésta es la primera razón y significación del derecho" ${ }^{23}$. Y, en efecto, lo que él describe como tal coincide -al menos en apariencia- con la tesis central del Aquinate sobre este asunto.

En el primer artículo de dicha cuestión, Tomás enfrenta el problema de la equivocidad del derecho y reconoce al menos cinco sentidos en los que habitualmente se usa la voz ius: el objeto de la justicia (lo justo o la misma cosa justa), el arte por el que se conoce aquella cosa justa, el tribunal que dictamina lo justo, la sentencia del juez y, por último, la ley ${ }^{24}$. Pero muy claramente explica que no a todas estas realidades conviene el nombre de derecho con la misma propiedad: como ha sucedido con tantos otros nombres, desde una predicación original y primaria se produce una derivación a otras realidades vinculadas con la primera, que reciben el nombre en razón de ese vínculo y de modo secundario: "es costumbre que los nombres sean apartados de aquello a lo cual han sido primeramente impuestos para significar otras cosas, como el nombre de medicina se impuso primeramente para significar el remedio que se presta al enfermo para sanarle, y después fue usado para significar el arte con que esto se hace" ${ }^{25}$. Y no cabe duda de cuál es, para el Aquinate, la acepción principal del derecho: "este nombre ius primeramente se impuso para significar la misma cosa justa" 26 , y a las demás realidades se les atribuyó el nombre por vía de analogía, pero con una predicación analógica en la que existe un analogado que es autoexplicativo -en lo que toca a la atribución de la razón análoga- y del cual dependen, en su explicación, los demás analogados. Esto es muy claro cuando se compara el modo en que Santo Tomás explica el ius como objeto de la justicia (esto es, como correspondiente a lo justo o la ipsa res iusta) con el modo en que explica las demás acepciones. En efecto, el primero lo explica simplemente con la descripción del objeto de la justicia (lo justo:

22 Suárez, Francisco S.I. Tractatus de legibus, ac Deo legislatore. Lib. 1, cap. 2.

23 “Unde D. Tho. 2.2. q.57. ar.1. hac dixit, esse prima rationem, et significatione iuris". Suárez, Francisco S.I. Tractatus de legibus, ac Deo legislatore. Lib. 1, cap. 2.

${ }^{24}$ Véase Tomás de Aquino. Summa Theologiae. II-II, q. 57, a. 1, in c. et ad 1.

25 "[C] onsuetum est quod nomina a sui prima impositione detorqueantur ad alia significanda, sicut nomen medicinae impositum est primo ad significandum remedium quod praestatur infirmo ad sanandum, deinde tractum est ad significandum artem qua hoc fit”. Tomás de Aquino. S. Th., II-II, q. 57, a. 1, ad 1.

26 “ $[\mathrm{H}]$ oc nomen ius primo impositum est ad significandum ipsam rem iustam”. Tomás de Aquino. S. Th., II-II, q. 57 , a. 1 , ad 1 . 
"lo que corresponde a otro según cierta igualdad" ${ }^{27}$ ) y la consiguiente constatación de la identidad entre tal objeto y aquello que llamamos derecho: "y esto es, ciertamente, el derecho" ${ }^{28}$, lo cual le permite responder a la cuestión planteada en el artículo, que era si el derecho es el objeto de la justicia: "por esto es manifiesto que el derecho es el objeto de la justicia" ${ }^{29}$. Las demás acepciones, en cambio, requieren una justificación que es menos inmediata, y que exige la referencia de aquellas otras realidades al derecho en su acepción principal. Así, no llamamos derecho a cualquier arte, sino sólo a aquél que permite la determinación del derecho como objeto de la justicia: "[el nombre de derecho] se derivó al arte por el cual se conoce qué sea justo" ${ }^{30}$; el tribunal toma el nombre de derecho porque allí es donde lo justo se determina: "después para significar el lugar en el que se adjudica el derecho, como se dice que alguno comparece en derecho" ${ }^{31}$; el oficio de juzgar tiene por objeto la determinación de lo justo, y sólo por esto se puede llamar derecho a la sentencia o resolución del juez (a pesar de que en algún caso singular resulte injusta): "se dice, también, que se adjudica el derecho por aquel a cuyo oficio pertenece el hacer justicia, incluso si aquello que decreta es inicuo" ${ }^{32}$; a la ley, por último, como expresamente señala Santo Tomás en la respuesta a la segunda objeción, se la llama derecho no porque propiamente lo sea, sino porque es una cierta razón de lo justo: "preexiste en la mente una cierta razón de aquellas acciones justas que la razón determina, al modo de una cierta regla prudencial. Y esto [...] se llama ley [...]. Y, de este modo, la ley no es el mismo derecho, propiamente hablando, sino alguna razón del derecho" ${ }^{33}$. Como se ve, la exposición de Tomás de Aquino sobre el significado de la voz ius no deja espacio para interpretaciones equívocas: el derecho es, principalmente, lo justo. También llamamos derecho, a veces, a otras realidades, pero no en razón de sí mismas, sino a causa de su vínculo con lo justo. La ley, singularmente, aunque con frecuencia la llamamos derecho, no es el derecho sino sólo una medida o regla universal del derecho.

Es llamativo que, en esta enumeración de acepciones del derecho, no aparece ninguna que corresponda al derecho como facultad o derecho subjetivo. No son

\footnotetext{
27 “[Q]uod respondet secundum aliquam aequalitatem alteri”. Tomás de Aquino. S. Th., II-II, q. 57, a. 1, in c.

28 "Et hoc quidem est ius". Tomás de Aquino. S. Th., II-II, q. 57, a. 1, in c.

29 "Unde manifestum est quod ius est obiectum iustitiae". Tomás de Aquino. S. Th., II-II, q. 57, a. 1, in c.

30 "[D]erivatum est ad artem qua cognoscitur quid sit iustum”. Tomás de Aquino. S. Th., II-II, q. 57, a. 1, ad 1.

31 "[U]lterius ad significandum locum in quo ius redditur, sicut dicitur aliquis comparere in iure". Tomás de Aquino. S. Th., II-II, q. 57, a. 1, ad 1.

32 "[D]icitur etiam ius quod redditur ab eo ad cuius officium pertinet iustitiam facere, licet etiam id quod decernit sit iniquum”. Tomás de Aquino. S. Th., II-II, q. 57, a. 1, ad 1.

33 "[I]llius operis iusti quod ratio determinat quaedam ratio praeexistit in mente, quasi quaedam prudentiae regula. Et hoc [...] vocatur lex [...]. Et ideo lex non est ipsum ius, proprie loquendo, sed aliqualis ratio iuris”. Tomás de Aquino. S. Th., II-II, q. 57, a. 1, ad 2.
} 
pocos los autores que han sostenido que esta acepción está presente, de un modo más o menos confuso, en otros textos de la obra del Aquinate ${ }^{34}$, pero, atendido el carácter extremadamente sistemático y ordenado de su pensamiento, sería sorprendente que usara con cierta habitualidad de una noción de derecho que jamás se ha detenido a explicar y que jamás ha hecho expresa como paralela a aquellas que enumera en la cuestión 57. Pero aun concediendo la posibilidad de que la noción se halle escondida, por aquí y por allá, en la obra del Aquinate -y que se explique esto por el hecho de que tal acepción del derecho ya circulaba en la teoría jurídica (al menos, en la canónica), aunque no todos los teóricos estuvieran perfectamente conscientes de su presencia-, no cabe duda de que el derecho llamado subjetivo no forma parte central de su exposición del derecho y la justicia.

Pues bien, atendido esto, se puede volver a Suárez y mostrar genuina estupefacción por la lectura que el jesuita granadino hace de aquellos pasajes de la Suma. Comienza el capítulo 2 del libro primero del De legibus con un análisis etimológico de la palabra ius, recogiendo distintas hipótesis de esa etimología. Y, sin pretensión de resolver el asunto, se inclina por dos explicaciones etimológicas que, aún sin poder determinar cuál sea la verdadera, sirven para explicar el significado de la voz, que es lo que le interesa. Las etimologías escogidas harían proceder la voz ius, la una, del verbo iubeo -cuyo participio pasado es iussum-, la otra, de iustitia. Según esta última etimología, el significado de ius sería lo justo: "ius significa lo mismo que justo y equitativo, que es el objeto de la justicia" ${ }^{35} \mathrm{y}$, atendido este significado, es necesario distinguir el ius de la ley, en estricta observancia de la doctrina tomista: "de aquí que Santo Tomás dijo que ésta es la primera razón y significación del derecho. Y de ello concluye sin problema, en la solución a la segunda objeción, que el derecho no es la ley sino lo que la ley prescribe o mide" ${ }^{36}$. Poco más adelante vuelve sobre la primera

\footnotetext{
${ }_{34}$ Tal cosa fue, de hecho, asumida acríticamente por la práctica totalidad del tomismo desde, precisamente, la escolástica espańola de los siglos XVI y XVII. Recién en el siglo XX la cuestión se plantea problemáticamente. Quizá el primer trabajo que aborda sistemáticamente la cuestión sea el de Jacinto Hering: "De iure subjective sumpto apud S. Thomam" (Angelicum 16, 1939), pero luego se ha vuelto muchas veces sobre el punto (véase, por ej.: Finnis, John. Aquinas. Moral, Political, and Legal Theory, Oxford, Oxford University Press, 1998, pp. 132-138; Hernández, Héctor. Derecho subjetivo. Derechos humanos. Doctrina solidarista, Buenos Aires, Abeledo-Perrot, 2000, pp. 259-269; Tierney, Brian. "Natural Law and Natural Rights. Old Problems and Recent Approaches", The Review of Politics, Vol. 64, $\mathrm{n}^{\circ}$ 3, 2002; Finnis, John. "Aquinas on ius and Hart on Rights: A Response to Tierney", The Review of Politics vol. 64, n³, 2002; Lisska, Anthony. "Human Rights Theory Rooted in the Writings of Thomas Aquinas", Diametros 38, 2013; Legge, Dominic O. P. “Do Thomists have Rights? Nova et Vetera, English Edition, vol. 17, n 1, 2019).

35 “[I] us idem significat, quod iustum, \& aequum, quod est obiectum iustitiae". Suárez, Francisco S.I. Tractatus de legibus, ac Deo legislatore. Lib. 1, cap. 2.

36 "Unde D.Tho.2.2.q.57.ar.1. hac dixit, esse prima rationem, et significatione iuris. Et inde optime concludit in solutione ad 2. ius non esse legem, sed potius esse id, quod lege praescribitur, seu mensuratur". Suárez, Francisco S.I. Tractatus de legibus, ac Deo legislatore. Lib. 1, cap. 2.
} 
etimología, aquella que hacía proceder el derecho de iubeo (que significa mandar, ordenar o disponer), según la cual "se ve que ius significa propiamente ley, pues la ley fue dada como mandato o imperio" ${ }^{37}$.

Hasta aquí, se podría leer a Suárez -desde Tomás de Aquino- pacíficamente y sin sobresaltos, pues su explicación del derecho parece situarse en una posición muy próxima a la del Aquinate. No obstante, esta primera impresión se disipa cuando se advierte el modo en que Suárez entiende el objeto de la justicia. La cuestión es que, inmediatamente después de declarar que ius significa, primariamente, lo justo y equitativo, explica esto en los siguientes términos:

"Y en base a esta posterior y estricta significación del ius, se suele llamar propiamente ius a cierta facultad moral que cada uno tiene, ya acerca de sus cosas, ya acerca de las cosas que le son debidas. Y así, en efecto, se dice dueño de la cosa del que tiene derecho en la cosa, y del operario se dice que tiene derecho al estipendio, por razón de lo cual se dice digno de su paga" 38 .

Quien tiene en mente los sentidos enumerados por el Aquinate podría, eventualmente, preguntarse si el jesuita está añadiendo, aquí, otra acepción del derecho: el derecho como facultad o potestad ${ }^{39}$, que luego se llamará derecho subjetivo; y que, como otros teólogos juristas españoles antes que él, complementa la explicación tomista del derecho con esta dimensión -no desarrollada por el Aquinate- que es la facultad moral ${ }^{40}$ que sobreviene a un sujeto como consecuencia de la determinación de algo como suyo en justicia. Pero el texto de Suárez es inequívoco: antes

37 “[P] roprie videtur ius legem significare: nam lex in iussionem, seu imperio posita est”. Suárez, Francisco S.I. Tractatus de legibus, ac Deo legislatore. Lib. 1, cap. 2.

38 "Et iuxta posteriorem, et strictam iuris significationem solet proprie ius vocari facultas quaedam moralis, quam unusquisque habet, vel circa rem suam, vel ad rem sibi debitam; sic enim dominus rei dicitur habere ius in re, et operarius dicitur habere ius ad stipendium, ratione cuius dicitur dignus mercede sua”. Suárez, Francisco S.I. Tractatus de legibus, ac Deo legislatore. Lib. 1, cap. 2.

39 Suárez usa ambos conceptos para designar el derecho en este sentido. Así, por ejemplo, en el De virtute et statu religionis dice que ius significa "cierta potestad moral para alguna acción o uso" ["morali quaedam potestate ad aliquem actum vel usum”. Suárez, Francisco. De virtute et statu religionis, Lib. VIII, cap. 5, 12]. O en De opere sex dierum: "llamamos derecho a la potestad moral de mérito, porque no añade al hombre alguna entidad o cualidad, sino sólo la facultad moral para usar de las cosas de las que es señor lícitamente y sin injusticia" ["Jus potestatem moralem merito appelamus, quia non addit homini aliquam entitatem, vel qualitatem, sed solam moralem facultatem, ut licite et sine alterius injuria possit uti rebus illis, quarum est dominus". Suárez, Francisco. De opere sex dierum. Lib. III, cap. 16, 9].

${ }^{40}$ Es Suárez, de hecho, quien especifica esta facultad como 'moral'. Y la razón de esto, según Baciero, es que "el hombre se pertenece o es dueño de sí gracias a la razón, y puede tener por ello una verdadera relación de dominio sobre sí mismo y sobre sus facultades, que en esa medida son suyas en el sentido riguroso de propiedades suyas, propiedades que no le pueden ser arrebatadas sin cometer con él una injusticia". Baciero, Francisco. "El concepto de derecho subjetivo y el derecho a la propiedad privada en Suárez y Locke”. Anuario Filosófico 45/2, 2012, p. 396. Es muy interesante, aunque no cabe en estas páginas, la cuestión de la ejemplaridad de la propiedad en la construcción moderna del derecho subjetivo. 
de explicar otros sentidos secundarios y derivados del ius, se concentra en los dos que él estima principales: lo justo y la ley. Y el derecho como facultad aparece, expresamente, como explicación de lo justo: retomando la definición de justicia del Digesto, para explicar el ius que es atribuido a cada uno en conformidad con la virtud -lo suyo de cada cual, el objeto de la justicia-, dice Suárez que es "aquella acción o facultad moral que cada cual tiene respecto de su cosa, o respecto de la cosa que de algún modo le pertenece" ${ }^{41}$. Y luego añade -para que a nadie le quepa ninguna duda del sentido de su afirmación-, que a esto "se le llama ius, y parece ser, propiamente, el objeto de la justicia" ${ }^{2}$.

Como puede verse, Suárez ha trasladado el eje de la consideración del derecho, desde la atribución objetiva de lo suyo de cada cual, a la facultad o poder moral -que, en todo caso, podría sobrevenir a esa atribución objetiva-, haciendo de estas dos cosas sólo una o, más bien, haciendo que la facultad moral eclipse la atribución objetiva de lo suyo. Pero esto no es todo: si retrocedemos a la explicación que ofrece de lo justo, después de haber señalado que, tomado el derecho en este sentido: como lo justo, la ley no es el derecho, sino lo que prescribe o mide el derecho, ańade la siguiente precisión: "en el mismo nombre de ley está contenida la fuerza de lo justo y la práctica del derecho, porque la verdadera ley debe prescribir lo igual y lo justo" ${ }^{43}$.

Santo Tomás, por cierto, en el texto al que hace referencia Suárez, no dice que la ley 'prescribe' el derecho, sino que la llama 'razón' o 'regla' del derecho. Superficialmente mirado, esto podría parecer una diferencia terminológica sin importancia, pero si se atiende al modo en que Suárez (en esto acompañado por Molina y Vázquez) entiende la objetividad moral, que depende de la posibilidad de extender el precepto legal a la determinación de todas las situaciones concretas, resulta que la regla o razón deja de ser esa medida universal que colabora en la determinación prudencial del derecho, y se transforma en una prescripción de lo justo concreto. De este modo, como advierte Carpintero, "el carácter moderno de la teoría de Suárez se muestra también en la extensión de la ley natural a las conclusiones más próximas que se extraen desde los primeros principios" ${ }^{44}$. Pero, por esta vía, lo justo no sólo se identifica con la facultad moral, sino también con

\footnotetext{
41 "[I]lla actio, seu moralis facultas, quam unusquisque habet ad rem suam, vel ad rem ad se aliquo modo pertinentem”. Suárez, Francisco S.I. Tractatus de legibus, ac Deo legislatore. Lib. 1, cap. 2.

42 "[V] ocatur ius, et illud proprie videtur esse obiectum iustitie". Suárez, Francisco S.I. Tractatus de legibus, ac Deo legislatore. Lib. 1, cap. 2.

43 "[I] $\mathrm{n}$ ipso nomine legis inesse vim iusti, et iuris colendi, quia vera lex aequum et iustum praecipere debet". Suárez, Francisco S.I. Tractatus de legibus, ac Deo legislatore. Lib. 1, cap. 2.

${ }_{44}$ Carpintero, Francisco. Historia breve del derecho natural. Op. cit., p. 134.
} 
la ley. Es lo que dice el texto citado: lo justo está contenido en la ley, y no sólo en sus principios, sino en su concreción práctica: "en el mismo nombre de ley está contenida la fuerza de lo justo y la práctica del derecho". Lo cierto es que ha aproximado tanto la ley a lo justo -al punto que la ley 'constituye' lo justo, prescribiéndolo-, que la distinción se diluye y las dos realidades se confunden. Tanto es así, que cuando Suárez repite el ejercicio que había hecho Santo Tomás, de mostrar cómo es que las otras acepciones del derecho son dependientes -en su razón de ius- de lo justo, sorprendentemente lo hace refiriendo esas realidades no ya a lo justo, sino a la ley: al acto del juez -sostiene- se le llama ius porque debe realizarse en conformidad con la ley; y al tribunal se le llama ius porque es el lugar en el que se aplica la ley; y al arte porque es el saber que permite aquella aplicación.

De este modo, el reclamo de Villey contra la modernidad jurídica, de reducir el derecho a una facultad moral determinada por la ley ("licencia para realizar tal o cual conducta, porque esa conducta es mandada, o permitida, por una ley" ${ }^{45}$ ), parece encontrar un blanco seguro en Suárez. Es menester advertir que la confusión de realidades jurídicas que en esta exposición se muestra no es consistente en toda la obra del jesuita granadino. Pareciera que la identificación entre ley y derecho objetivo no es plenamente consciente en el propio Suárez, al punto que puede afirmar, en otro lugar del mismo capítulo, que "la ley constituye la equidad o es su medida y regla, pero no es propiamente la misma equidad" 46 . Sin embargo, una tal afirmación -y otras muchas semejantes que se pueden encontrar a lo largo y ancho de su obra-, sólo dejan constancia de las tensiones y contradicciones internas del corpus suareciano, y no son suficientes para intentar una interpretación que descubra una unívoca coherencia de su doctrina con la tradición clásica.

\section{Conclusión. ¿Es Suárez moderno?}

En la INTRODUCCión de estas páginas se decía que la revolución jurídica de la modernidad se podía resumir en tres fenómenos indisolublemente vinculados entre sí: el eclipse de lo justo, el amanecer de los derechos y la consecuente redefinición de la ley. Lo expuesto sobre la concepción suareciana del derecho parece ajustarse perfectamente a esta descripción: ha sobrepuesto el derecho como facultad al derecho como lo justo y ha modificado el concepto de ley al extremo de confundirlo,

45 Villey, Michel. Le droit et les droits de l'homme. Paris, Presses Universitaires de France, 1983, p. 127.

46 "[L] ex constituit aequitatem, vel est mensura et regula ejus; non est proprie ipsa aequitas". Suárez, Francisco S.I.

Tractatus de legibus, ac Deo legislatore. Lib. 1, cap. 2. 
al menos parcialmente, con este extraño derecho objetivo/subjetivo (el problema de la ley en Suárez, como se sabe, es bastante más amplio y complejo que el de su carácter constitutivo o prescriptivo del derecho, pero no cabe detenerse -en estas páginas- en la cuestión del presunto imperativismo voluntarista del concepto suareciano de ley). Así, pues, lo aquí mostrado debería bastar para concluir -contra lo que han sostenido muchos iusnaturalistas tomistas- que Suárez no puede ser considerado, simplemente, como un continuador de la tradición de la teoría clásica de la ley natural en la versión de la que Santo Tomás es el mayor exponente. Su doctrina jurídica no es un desarrollo de las ideas tomistas en la materia, sino que expresamente se aparta del Aquinate en ciertas cuestiones centrales de la teoría de la ley y el derecho natural, como son el sentido de lo justo y su relación con los principios y preceptos legales.

Sin embargo, esto no es suficiente para incorporar a Suárez entre los fundadores de la modernidad jurídica. Salvando las limitaciones de una categoría así, y asumiendo una definición -más o menos estipulativa- de la modernidad filosófica por su dependencia del nominalismo, y de la modernidad jurídica por las consecuencias de éste en el ámbito del derecho (y que, como dijimos en la primera parte de este trabajo, aparecen como notas comunes de las diversas teorías jurídicas modernas, no obstante sus distancias), lo que tendríamos que encontrar en Suárez -para sumarlo a aquella lista que incluye a Grocio, Hobbes, Pufendorf, Leibniz, Locke...- es una negación de la naturaleza humana universal como supuesto de la inteligibilidad del orden jurídico; el reemplazo de la misma por un individualismo metafísico y jurídico; y la consecuente afirmación de una libertad individual negativa como fuente de sentido de las realidades jurídicas. Sostener, como ha hecho Villey, que estas son notas del pensamiento suareciano (y aun de toda la escolástica española) es, sin duda alguna, una infundada exageración. Pero, a su vez, la negación de la exageración no debe llevar a la exageración contraria, que es la negación de toda traza de nominalismo en Suárez, y la afirmación de su perfecta continuidad con Tomás de Aquino. Ya se ha visto que no hay tal continuidad en lo que toca a sus conceptos de derecho y ley. Ahora bien, ¿se puede afirmar que esa discontinuidad responde a la adopción de los principios del nominalismo? Basta mirar el orden de los temas de sus Disputaciones metafísicas para descartar tal posibilidad, pero también es cierto que, a pesar de una metafísica fundamentalmente no nominalista (incluso se podría decir que se aleja de Santo Tomás más en dirección al esencialismo que al nominalismo), tensiones (confusiones, contradicciones) como las que se descubren en su teoría jurídica también aparecen en su filosofía primera. Así, por ejemplo, Suárez puede decir que "la aptitud de la naturaleza común para ser en muchos no es algo conve- 
niente a la misma naturaleza tal como existe en el particular real” ${ }^{47}$. Y que esto significa, para él, la introducción de un principio de división entre una naturaleza universal y las naturalezas particulares lo deja muy en claro poco más adelante: "la naturaleza universal no existe en muchos sino por identidad con cada uno de los singulares; pero tal naturaleza, identificada con un individuo no puede, ella misma, identificarse con otros según la realidad [secundum rem] y según la existencia real" ${ }^{48}$. Lo cual, inevitablemente, supone una cierta disminución del carácter auténticamente común de las naturalezas de los individuos y, a la vez, una suerte de esencialización del individuo, que por momentos se vuelve expresa: "la naturaleza existente en acto no se distingue de la naturaleza que es real por el individuo y, por ello, de este modo no puede tener unidad real que repugne a la individuación, como sería la unidad común" ${ }^{49}$. Todos estos textos pertenecen a la cuarta sección de la sexta disputación. Como para descartar que se trate de un accidente puntual, Suárez introduce, mucho después (en la décimo tercera disputación), una de las consecuencias de tal esencialización del individuo, que es la esencialización de la materia (principio de la individuación en la metafísica tomista ${ }^{50}$ ): "la materia creada por Dios y existente en el compuesto tiene alguna esencia real o, de otro modo, no sería ente real; pero la esencia de la materia no es constituida intrínsecamente en su ser de esencia por la forma; luego, por sí misma tiene su entidad de esencia, de cualquier clase que sea" ${ }^{51}$, de manera que muestra una persistente coherencia en unas posiciones metafísicas que se aproximan a la exaltación nominalista de la realidad del individuo y el oscurecimiento de la realidad del universal (o, al menos, en el caso de Suárez, el distanciamiento de la realidad del universal respecto de la realidad 'existente en acto').

Como ya hemos dicho, es innegable la continuidad lógica que existe entre el individualismo (que sigue al nominalismo) y la exaltación del derecho subjetivo

\footnotetext{
47 "[A]ptitudo naturae communis ut sit in multis non est aliquid conveniens ipsi naturae prout a parte rei existit". Suárez, Francisco. Disputationes Metaphysicae. Disputatio VI, sectio IV, 2.

48 " $[\mathrm{N}]$ atura universalis non existit in multis nisi per identitatem cum singulis eorum; sed talis natura identificata uni individuo non potest eadem secundum rem et secundum existentiam realem identificarii aliis". Suárez, Francisco. Disputationes Metaphysicae. Disputatio VI, sectio IV, 4.

49 " $[\mathrm{N}]$ atura actu existens non distinguitur ex natura rei ab individuo, et ideo ut sic non potest habere unitatem realem repugnantem individuationi qualis esset unitas communis”. Suárez, Francisco. Disputationes Metaphysicae. Disputatio VI, sectio III, 7.

50 Precisamente la esencialización de la materia es lo que le impide a Suárez reconocerla como principio de individuación, lo que le lleva a otro de los puntos que le aproximan a Ockham: la identificación de la individuación con la unidad entitativa. Véase Suárez, Francisco. Disputationes Metaphysicae. Disputatio V.

51 " $[\mathrm{M}]$ ateria creata a Deo et in composito existens habet aliquam essentiam realem, alioqui non esset ens reale; sed essentia materiae non constituitur intrinsece in suo esse essentiae per formam; ergo, per seipsam habet suam qualemcumque entitatem essentiae”. Suárez, Francisco. Disputationes Metaphysicae. Disputatio XIII, sectio VI, 9.
} 
como la primera y primordial realidad jurídica, porque la reducción de la realidad al individuo, con la consiguiente incomunicación esencial de unos y otros individuos, no puede sino redundar en la negación de una atribución objetiva de lo suyo de otro anterior al poder individual para reclamar el bien propio, ya que aquella atribución supone, precisamente, el reconocimiento de un bien bajo algún respecto universal o común. Si aquí se estuviera analizando la obra de, por ejemplo, Hobbes, no habría ningún problema para establecer esa continuidad del individualismo nominalista a la exaltación del derecho subjetivo porque, de hecho, esa continuidad es expresa. En Suárez, sin embargo, no hay tal cosa. Lo que parece haber es la integración, más o menos inconsciente, de elementos dispersos pertenecientes a cuerpos teológicos, filosóficos y jurídicos dispares y aun contradictorios. ¿Es, Suárez, uno de los fundadores de la modernidad jurídica? Tanto cuanto corresponda ese título al autor de una obra que, más bien, parece el más claro -y estertóreo- ejemplar del agrietamiento y debilitación de la tradición jurídica clásica y medieval. 


\section{REFERENCIAS BiBLIOGRÁFICAS}

Baciero, Francisco. "El concepto de derecho subjetivo y el derecho a la propiedad privada en Suárez y Locke". Anuario Filosófico 45/2, 2012.

Carpintero, Francisco. "Los escolásticos españoles en los inicios del liberalismo político y jurídico". Revista de Estudios Histórico-Jurídicos 25, 2003.

- "Las personas como síntese: la autonomía en el derecho". En Leite De Campos, Diego y Juny De Abreu Chillenato, Silmara. Pessoa humana e direito. Coimbra, Edicoes Almedina, 2009.

- Historia breve del derecho natural. Madrid, Colex, 2009.

Finnis, John. Aquinas. Moral, Political, and Legal Theory, Oxford, Oxford University Press, 1998.

- "Aquinas on ius and Hart on Rights: A Response to Tierney", The Review of Politics vol. 64, n 3, 2002.

Folgado, Avelino. Evolución histórica del concepto de derecho subjetivo. Estudio especial de los teólogos-juristas españoles del siglo XVI. San Lorenzo de El Escorial, Pax Juris - Escurialensium Utriusque Studiorum Scerpta, 1960.

Guzmán Brito, Alejandro. El derecho como facultad en la neoescolástica española del siglo XVI. Madrid, Iustel, 2009.

Hering, Jacinto: "De iure subjective sumpto apud S. Thomam". Angelicum 16, 1939.

Hernández, Héctor. Derecho subjetivo. Derechos humanos. Doctrina solidarista, Buenos Aires, Abeledo-Perrot, 2000.

Legge, Dominic O. P. "Do Thomists have Rights? Nova et Vetera, English Edition, vol. 17, $\mathrm{n}^{\circ} 1,2019$.

Lisska, Anthony. "Human Rights Theory Rooted in the Writings of Thomas Aquinas”, Diametros 38, 2013.

Megías, José Justo. Propiedad y derecho natural en la historia. Cádiz, Servicio de Publicaciones de la Universidad de Cádiz, 1994.

- "El derecho subjetivo en el derecho romano (un estado de la cuestión)", en Revista de Estudios Histórico-Jurídicos 25, 2003.

Pennington, Kenneth. "The History of Rights in Western Thought". Emory Law Journal, vol. 47, 1998. 
Rego, Francisco. La polémica de los universales: sus autores y sus textos. Buenos Aires, Gladius, 2005.

Reid, Charles J. Jr. "The Canonistic Contribution to the Western Right Tradition: An Historical Inquiry”. Boston College Law Review vol. 33, 1991.

Rodríguez Puerto, Marcial. "Escolásticos españoles y subjetivismo moderno (un comentario sobre el concepto de derecho en Luis de Molina y Francisco Suárez)". Ingenium 5, 2011.

Sol, Thierry. "La notion de ius en droit sacramentaire chez Gratien et les Décrétistes". Ius Ecclesiae. Rivista internacionales di Diritto Canonico. Vol. XXVII, n ${ }^{\circ}$ 2, 2015.

Suárez, Francisco S.I. De opere sex dierum.

- De virtute et statu religionis.

- Disputationes Metaphysicae.

- Tractatus de legibus, ac Deo legislatore.

Tierney, Brian. The Idea of Natural Rights. Studies on Natural Rights, Natural Law and Church Law, 1150-1625. Grand Rapids-Michigan, B. Eerdmans Publishing Co., 2001.

- "Natural Law and Natural Rights. Old Problems and Recent Approaches", The Review of Politics, Vol. 64, n 3, 2002.

Tomás de Aquino O.P. Summa Theologiae.

Villey, Michel. La formation de la pensée juridique moderne. Paris, Presses Universitaires de France, $2^{\text {a }}$ edición, 2013.

Villey, Michel. Le droit et les droits de l'homme. Paris, Presses Universitaires de France, 1983.

Widow Lira, Felipe. "Los orígenes de la noción moderna de derecho subjetivo. ¿Ha sido superada la tesis de Michel Villey?”. Forum. Suplemment to Acta Philosophica, vol. 5/2, 2019.

DOI: https://doi.org/10.15366/bp2021.26.010

Bajo Palabra. II Época. No26. Pgs: 201-220 